Commonplace • Series 1.3: Global Transition to Open

\title{
Building a Framework \\ Together for Assessing OA Book Publishing Models
}

Emily Farrell, Emily Poznanski, Charles Watkinson

Published on: Nov 16, 2021

DOI: $10.21428 / 6 \mathrm{ffd} 8432.185 \mathrm{~d} 3532$

License: Creative Commons Attribution 4.0 International License(CC-BY 4.0). 


\section{Introduction}

The conversation about open access (OA) models and how to assess them has largely centered on STEM journals. STEM journals have made a faster and more complete move to digital than books and take up a significantly larger portion of collections budgets. The high cost of STEM journals has meant that the financial need for a change of approach in libraries has been more pressing than humanities and social sciences (HSS) books. The largest move to OA journals has been through article processing charge (APC) based approaches and "transformative agreements" through which libraries seek to control overall institutional spending. But this predominant model for moving journals to OA will not work for book publishing. Neither will the ways that libraries assess the value and impact of OA book programs. Here we, three university presses, call on libraries, with which we share many values, to establish a common framework for OA book model assessment and sustainability.

Academic books remain core to scholars in humanities and social science (HSS) disciplines, yet these are disciplines where funds for OA charges are near non-existent. The increase in contingent positions in academia results in more movement and less consistency in funding for researchers. Books are more costly to produce. They are longer and involve editorially-intensive publishing processes. Book processing charges (BPCs) are, therefore, usually much higher than APCs. Negotiating transformative agreements is time-consuming and requires staff that smaller presses and smaller libraries often do not have. Data or metadata is often complex or missing for books and data analysis is likewise challenging, with the added layer of HSS scholars often being wary of metricization. Reliance on models that depend on BPCs will simply not lead to a sustainable or equitable OA future for the HSS book.

\section{Case Studies Toward Solutions}

The MIT Press, Central European University Press, and University of Michigan Press have been pioneers in developing and implementing models for OA book publishing that do not require authors to pay. All three presses are establishing replicable, rhizomatic models that provide OA options for small- to mid-sized book publishers. In all three cases, the call to action for a global community of libraries is to switch their investments from buying books for local use to working collectively to open content for all. The three models encourage collective behavior through "incentivized" support, 
providing supporting libraries with unique access to restricted backlist collections. Each press has addressed the differing needs of their publishing history and program with models that have these commonalities, but differ in several ways.

In 2019, the MIT Press received support from the Arcadia Fund to develop a model that would enable a more comprehensive opening of new Press monographs through collective library support. When successful, Direct to Open (D2O). will open around 90 books on publication in 2022. The program calls on libraries to come together to support OA monographs, thereby distributing costs across libraries worldwide and keeping costs sustainable. Once the Press meets its financial goal, any library contributions above the set financial threshold will be redistributed. The more libraries that participate, the higher the likelihood that fees will decrease. Libraries are incentivized to participate through the benefit of term access to the Press monograph backlist, around 2,500 titles. Participating libraries gain access regardless of whether D2O is successful. If D20 does not reach the needed financial threshold for the 2022 program, libraries do not pay and will retain the term backfile access benefit. Participating libraries also receive substantial discounting on the Press's trade ebooks collection. D2O is an annual commitment, though libraries are encouraged to support the model for three years.

The $\underline{\mathrm{CEU}}$ Press Opening the Future program was launched in cooperation with $\underline{\mathrm{COPIM}}$, a Research England and Arcadia-funded initiative that aims to establish some of the missing infrastructures for open access monographs. One of the missing components identified by COPIM was the business models needed to transition existing university presses to equitable models for open access. This partnership resulted in Opening the Future, a model designed for small to medium-sized university presses with a substantial backlist. It combines a membership and subscription model to allow all librarians with or without an OA fund to participate. Packages of paywalled backlist content grouped by CEU Press' subject specialization in History or Political Science or high-usage titles are sold to libraries for their own collections. The revenue from these sales goes entirely towards funding the frontlist to become open access. The model also uses "dynamic scaling," which means there is no built-in threshold. So as more libraries join, the more books are made open every year and it is not an all or nothing commitment. When the press raises enough funding to make another book open access, it makes the announcement well in advance of publication.

The U-M Press Fund to Mission program gets its name from the contention that university presses were created by their parent institutions not to sell books but to 
enable the broad dissemination of the knowledge they contain. If knowledge dissemination is a university's core mission, the press should be funded as part of that mission. In practice, the business model draws funds equally from three sources, each representing a beneficiary of university press publishing. The three sources are the parent institution that chose to establish the press, the community of libraries that facilitate access for readers, and (only where available) the funders that support authors' work through title subventions. Like its cousins, Fund to Mission leverages term access to a backlist collection of around 2,000 books to help libraries justify supporting OA for the frontlist. During a transitional phase, the Press will increase the OA availability of its 80 titles-per-year monograph program over several years (50\% OA in 2022, 75\% OA in 2023). The program also emphasizes open-source infrastructure (all books are hosted on the open-source platform, Fulcrum), open standards, and open governance.

\section{Indicators for Assessment}

Over the last year, despite the myriad pressures exacerbated by COVID, libraries have responded enthusiastically, investing time and money in support. Many institutions have developed or are developing criteria for investing in OA books initiatives. A key request for transparency drives a need to establish systems to report impact to libraries. To move these models from experimental to sustainable, cooperation between university presses and libraries on frameworks for assessing value and impact on both sides will be crucial.

But by what metrics are we to judge return on investment for OA books? Collections development librarians look for "cost per use" to benchmark against gated content. Scholarly communication librarians ask about "author affiliation." Both are stakeholders, and respective metrics are complex for OA books. Libraries advance the missions of their parent institutions, reflect the personalities of their leaders, and respond to different national and regional environmental pressures. However, we have encountered three common principles and values when discussing our programs with libraries. What indicators can we develop together to assess these?

\section{1|A strong interest in advancing diversity, equity, and inclusion}

While we recognize that OA books models cannot solve systemic inequality alone, our models aim to offer replicable measures that center diversity, equity, and inclusion. Many monographs in our publisher programs are used in coursework. Beyond OA 
alone, metrics that consider a press's broader commitment, including the implementation of strategies that aim to diversify staff and authors, drawing on resources such as the anti-racism toolkits developed by C4DISC. Increasing the amount of open content increases the ability for students to access this work for free, with resources like Oppen Syllabus Explorer improving discovery for students.

\section{2|A passion for public engagement and the opportunities that access to expert knowledge offers to advance social change}

Impact beyond standard measures like citations and downloads, impact factor, and affiliation data are necessary to account for OA books' value in driving public engagement. Efforts like HuMetricsHSS and Dora can be incorporated to understand reach in broader ways. Extending from the move away from author-pays models, we want to focus on the global engagement with our publications, as well as readership from the wider public and measures of social impact as demonstrated in the Digital Science Report on UN SDGs.

\section{3|A desire to support digital scholarship and the sorts of digital affordances that OA makes possible}

The degree to which our programs promote innovation can be hard to measure. In Europe, economic innovation has been a focus of policy movements toward open. For books, innovation in research practices has been an interest in the US. Humanities deans are interested in developing new forms of book publication; short-form works, multimedia, etc. Interdisciplinarity has also been closely tied to innovation, the opportunity for serendipitous discovery across disciplinary boundaries. Qualitative metrics may be most effective, highlighting exemplars of new forms of book-based scholarship made possible by OA.

\section{Conclusion}

The measures suggested above are an opening gambit for engagement. Each of our presses has benefited from many discussions with libraries in developing and implementing our models, including working with consortia to run beta versions of our models to gain library perspective and adjust parameters. Sustaining them will involve cooperation to understand their impact in a granular and values-led way. Collective OA books models are still new, the landscape is evolving, and we see exciting opportunities to shape its topography together. 